\title{
Effect of thyme extract supplementation on lipid peroxidation, antioxidant capacity, PGC-1a content and endurance exercise performance in rats
}

Mostafa Khani ${ }^{1}$, Pezhman Motamedi ${ }^{2}$, Mohammad Reza Dehkhoda², Saeed Dabagh Nikukheslat ${ }^{1}$ and Pouran Karimi ${ }^{3^{*}}$

\begin{abstract}
Background: Athletes have a large extent of oxidant agent production. In the current study, we aimed to determine the influence of thyme extract on the endurance exercise performance, mitochondrial biogenesis, and antioxidant status in rats.

Methods: Twenty male Wistar rats were randomly divided into two groups receiving either normal drinking water (non-supplemented group, $n=10$ ) or thyme extract, $400 \mathrm{mg} / \mathrm{kg}$, (supplemented group, $n=10$ ). Rats in both groups were subjected to endurance treadmill training $(27 \mathrm{~m} / \mathrm{min}, 10 \%$ grade, $60 \mathrm{~min}$, and 5 days/week for 8 weeks). Finally, to determine the endurance capacity, time to exhaustion treadmill running at $36 \mathrm{~m} / \mathrm{min}$ speed was assessed. At the end of the endurance capacity test, serum and soleus muscle samples were collected and their superoxide dismutase (SOD) and glutathione peroxidase (GPX) activity, as well as malondialdehyde (MDA) concentration were measured. Protein expression of PGC-1a, as a marker of mitochondrial biogenesis, was also determined in the soleus muscle tissue by immunoblotting assay.

Results: Findings revealed that the exhaustive running time in the treatment group was significantly $(p<0.05)$ prolonged. Both serum and soleus muscle MDA levels, as an index of lipid peroxidation, had a threefold increase in the thyme extract supplemented group ( $\mathrm{t}_{18}=8.11, p<0.01 ; \mathrm{t}_{18}=4.98, p<0.01$ respectively). The activities of SOD and GPx of the soleus muscle were significantly $(p<0.05)$ higher in the non-supplemented group, while there was no significant difference in serum SOD, GPx activities, and total antioxidant capacity between groups. Furthermore, thyme supplementation significantly $(p<0.05)$ decreased PGC-1a expression.

Conclusions: Thyme extract supplementation increased endurance exercise tolerance in intact animals, although decrease of oxidative stress and regulation of the PGC-1a protein expression are not considered as underlying molecular mechanisms.
\end{abstract}

Keywords: Athletic performance, PGC1alpha protein, Reactive oxygen species, Thyme

\footnotetext{
*Correspondence: pouran.karimi@yahoo.com

${ }^{3}$ Neurosciences Research Center, Tabriz University of Medical Sciences,

Tabriz, Iran

Full list of author information is available at the end of the article
} 


\section{Background}

Reactive oxygen species (ROS) which are produced during aerobic metabolism may oxidize biomolecules and react with different cell sections [1]. Although a physiologically appropriate ROS levels act as a biological messenger, initiating cellular signaling cascades via the process of electron transfer to promote adaptive responses within the body [1], uncontrolled oxidative events can result in lipid, protein and DNA structural damage within cells, leading to an impaired cellular function, a condition generally referred to as oxidative stress [2]. Indeed, imbalances between exercise-induced stress and recovery may impair physiological accommodations, leaving the individual in a maladaptive condition where performance may deteriorate or even decline [3-5]. In fact, extended periods of intensified exercises may result in an accumulation of fatigue, leading to short-term (non-functional over-reaching) and long-term (over-training) decrements in performance capacity [6]. Excessive exercise-induced ROS may also contribute to disruptions in the biological processes, including the metabolic, neuroendocrinological, physiological, psychological, and immunological systems [7].

During exercise, the raised oxidant production in skeletal muscle is regulated by a synergistic response between the endogenous antioxidant system, and the vitamin and mineral antioxidants ingested as part of a well-balanced nutritional diet [8]. The antioxidant system immediately adapts to physical training stimuli to counterbalance the potentially detrimental effects of excessive exercise-induced ROS and to maintain the redox-controlled signaling pathways [9]. However, it has been proposed that those athletes, who sustain an augmented amount of oxidative stress during frequent bouts of exercise, may need a greater extent of exogenous antioxidants to preserve health and enhance performance [10-12]. Therefore, the use of exogenous antioxidant supplements to maintain antioxidant status has been extensively studied. For example, 5 days of supplementation with tart cherry juice (active ingredients: $600 \mathrm{mg}$ phenolic compounds and $560 \mathrm{mg}$ flavonoid compounds) diminished oxidative damage (malondialdehyde and protein carbonyls) and reduced C-reactive protein [CRP] and interleukin [IL]-6, inflammatory cytokines, $48 \mathrm{~h}$ post-marathon in 20 well-trained runners [13]. Similar reductions in post-exercise measures of oxidative stress (F-isoprostanes) and muscle damage (creatine kinase, $\mathrm{CK}$ ) have been discovered in 12 collegiate soccer players who ingested a mixture of antioxidant substances (Resurgex ${ }^{\ominus}$ and Resurgex Plus ${ }^{\oplus}$ ) for a 3-week period compared to a placebo (isocaloric equivalent) [14]. These findings defend the hypothesis that antioxidant supplementation may help athletes to cope better with intensified training periods and prevent excessive
ROS-induced reductions in performance capacity during exhausting exercise $[10,11]$.

Natural antioxidant such as the coenzyme Q10, quercetin [15], and resveratrol [16] by having bioenergetics and antioxidant system reinforcement role, induce skeletal muscle and brain mitochondrial biogenesis and thus can delay fatigue and improve exercise performance [17]. The principal reason for such effects seems to be polyphenols compounds. Polyphenols are poly-hydroxylated phytochemical compounds containing two main groups of phenolic acids and flavonoids. Flavonoids are a large family of benzo-[gamma]-pyrone derived low molecular weight phenols, which are present in more fruits and vegetables in different amounts [18-20].

According to available evidence, it seems that flavonoid supplementation increases the performance in endurance activities via an increase in expression of peroxisome proliferator-activated receptor coactivator $(\mathrm{PGC}-1 \alpha)$ as the "master regulator" of biogenesis [15] and skeletal muscle angiogenesis [21].

Meanwhile, an herbal plant which contains a high flavonoid and antioxidant properties [22], and is widely used in traditional medicine, but its absence in the researches related to sports supplements is felt, is thyme. Thymus migricus Klokov \& Desj.-Shost, a member of Lamiaceae family is a Mediterranean native herb which traditionally is used as food additive and its main essence (thymol) is widely used in several medicinal products [22]. Thyme extract has anti-inflammatory, disinfectant, anti-worm, appetizing, sedative [23] and sexually stimulating effects [24]. Regarding the antioxidant properties of thymus migricus Klokov \& Desj.-Shost due to its phenolic compounds such as flavonoids and phenolic acids as well as thymol, gamma-terpinene, which are even higher than artificial antioxidants like butylated hydroxytoluene [22], we hypothesized that it may prevent strenuous exercise-induced ROS production and enhance exercise performance, especially in endurance sports. Therefore, the current study aimed to determine the influence of thyme extract supplementation on oxidative stress (lipid peroxidation), antioxidant status, PGC- $1 \alpha$ content and endurance performance after a 2-month period of endurance training.

\section{Methods \\ Animals}

Twenty male Wistar rats were obtained from Pasteur Institute (Tehran, Iran) at the age of 8 weeks. Experiments were performed after a 3-dayadaptation period. Animals were housed individually in regular cages under 12:12-h light-dark cycle, $22^{\circ} \mathrm{C}$ temperature, and $50 \%$ relative humidity.

Rats were divided randomly into two groups and received standard rat chow containing protein with all the 
essential amino acids (30\%), carbohydrates (40\%) and lipids (30\%) as well as either water ad libitum (non-supplemented group, $n=10$ ) or thyme hydro-alcoholic extract dissolved in distilled water to the desired concentration $(400 \mathrm{mg} / \mathrm{kg})$ according to their daily water consumption $(30 \mathrm{ml}$ ) (supplemented group, $n=10)$. All experimental trials were carried out at the beginning of the dark cycle $(19: 00 \mathrm{~h})$. Throughout the experiments, there were no significant differences in the mean food consumption (about $20 \mathrm{~g}$ per day per rat) and body weight of the animals in the two groups.

\section{Treadmill performance (maximal endurance capacity)}

Rats in both groups were subjected to endurance running on a motorized treadmill 5 days/week. Rats started running for $10 \mathrm{~min} /$ day at $10 \mathrm{~m} / \mathrm{min}$ and $10 \%$ grade. The speed and duration were progressively enhanced during the next weeks until each rat was running continuously for a period of $1 \mathrm{~h} /$ day at $27 \mathrm{~m} / \mathrm{min}$ for 8 weeks.

Endurance capacity was assayed by treadmill running to fatigue after the end of the training period. In this step, animals were compelled to run on a motorized treadmill (5/lane) at a speed of $36 \mathrm{~m} / \mathrm{min}$ and a grade of $8 \%$ until they were exhausted [15]. Exhaustion was defined as the inability of the rat to maintain an appropriate pace despite continuous hand prodding for $1 \mathrm{~min}$, at which time the rat was removed from the treadmill, and its run time recorded.

\section{Hydro-alcoholic extraction preparation}

A $30 \%(\mathrm{~W} / \mathrm{V})$ plant material was made in methanol/ water $(80: 20, \mathrm{v} / \mathrm{v})$ at $25{ }^{\circ} \mathrm{C}$, stirred $150 \mathrm{rpm}$ for $1 \mathrm{~h}$ and filtered through Whatman No. 4 paper. The extra hydro-alcoholic mixture was added to the remnant for extracting the residue. The pooled extracts were dried at $35{ }^{\circ} \mathrm{C}$ under reduced pressure (rotary evaporator Büchi R-210, Flawil, Switzerland) and then further lyophilized (FreeZone 4.5, Labconco, Kansas City, MO, USA).

\section{Sample preparation}

Twenty-four hours after the last endurance performance test, rats were deeply anesthetized. Blood samples were withdrawn from the heart and collected into heparinized glass test tubes. Sera and blood cells were separated by centrifugation at $2500 \mathrm{rpm}$ for $10 \mathrm{~min}$ at room temperature and subjected to biochemical analyses. The soleus muscles were rapidly excised, frozen, and kept at $-80{ }^{\circ} \mathrm{C}$.

\section{Western blot analysis}

The expression of PGC-1 $\alpha$ was determined by immunoblotting assay. Briefly, a 10\% (W/V) soleus muscle homogenate was made in ice cooled RIPA lysis buffer
(Sigma-Aldrich, cod.R0278) containing Protease Inhibitor Cocktail (Roche, cod.11836153001). After mincing by dounce homogenizer and incubating in $4{ }^{\circ} \mathrm{C}$ for $30 \mathrm{~min}$, the supernatant was collected by centrifugation at $11,000 \times \mathrm{g}$ for $15 \mathrm{~min}$ at $4{ }^{\circ} \mathrm{C}$ precooled centrifuge (Bekman) and subjected to Bradford assay to determine the protein concentration. The supernatant was mixed (1:1) with Laemmli $2 x$ sample Buffer $(50 \mathrm{mM}$ Tris (pH 6.8), 10\% Glycerol, 2\% SDS, 0.01\% Bromophenol Blue) freshly received 2.5\% Beta-ME and boiled for $5 \mathrm{~min}$. SDS-PAGE (10\% gels) was applied to separate the proteins, afterwards blotted to polyvinylidene difluoride (PVDF) membrane (sigma, cod.427152). Membranes were blocked with PBS-BSA-T buffer, PBST, $(8 \mathrm{mmol} / \mathrm{L}$ phosphate saline buffer ( $\mathrm{pH} 7.4), 3 \%$ BSA, $0.1 \%$ Tween 20) at room temperature for $2 \mathrm{~h}$ and then exposed to primary antibody against PGC- $1 \alpha$ (dilution 1:1000, A cod. ab54481) at $4{ }^{\circ} \mathrm{C}$ in a shaker incubator (Behdad, Tehran, Iran) overnight. After undergoing three $5 \mathrm{~min}$ of washing steps with PBS-T, the membranes were incubated with horseradish peroxidase (HRP) conjugated goat anti-rabbit antibody (diluted 1:10000) (ab6721, Abcam, UK) for $1 \mathrm{~h}$ at $25{ }^{\circ} \mathrm{C}$ under gentle agitation. Equal volumes of ECL substrate solution (Bio-Rad, cod. 102030396) and Luminol/enhancer solution (Bio-Rad, cod. 102030394) were used to visualize the protein bands. Image $J$ software was applied to measure the density of the bands.

Local background was subtracted from density volume to obtain a net density of each band. The relative intensity for each sample was calculated by dividing the net intensity of target protein (PGC-1 $\alpha$ ) to the net intensity of the $\beta$-actin protein band as reference.

\section{Colorimetric assays}

The activities of antioxidant enzymes, including superoxide dismutase (SOD) and glutathione peroxidase (GPx) and concentration of malondialdehyde (MDA) and capacity of total antioxidant of all samples were evaluated by colorimetric assays in the hemolysates, soleus muscle homogenates or sera prepared as briefly follows. After dissection, soleus muscle was weighed and homogenized in 1:3 volume of ice cooled lysis buffer (50 mM Tris-HCl; pH 7.4, $0.5 \mathrm{M}$ sucrose, $0.2 \mathrm{M} \mathrm{KCl}$, $1 \mathrm{mM}$ EDTA) containing cocktail protease inhibitor (Roche, Switzerland) and $0.5 \mathrm{mM}$ DTT. Centrifugation at $12,000 \mathrm{~g}$ for $30 \mathrm{~min}$ at $4{ }^{\circ} \mathrm{C}$ was performed to obtain the supernatant that was used to measure the activity of enzymes.

The total GPx and SOD activities were measured by commercially available Ransel and Ransod kits (Randox company, Crumlin, UK) respectively.

The superoxide dismutase activity was determined based on the rate of inhibition of reaction between2-(4- 
iodophenyl)-3-(4-nitrophenol)-5-phenyltetrazoliumchloride (I.N.T.) and superoxide radicals $\left(\mathrm{O}_{2}{ }^{\circ}\right)$ produced by the xanthine oxidase. Absorbance was read in wavelength of $505 \mathrm{~nm}$. Catalytic activity of GPx in oxidation of GSH (reduced) to GSSH by cumenehydroproxide was measured. GSH was concomitantly produced using glutathione reductase and NADPH. The absorbance was measured by UV filter at $340 \mathrm{~nm}$. The activities of GPx and SOD were expressed as U/g hemoglobin or U/g protein in hemolysate or tissue homogenate respectively.

Thiobarbituric acid (TBA) reactive substances test was applied for measurement of MDA as a major lipid peroxidation product in serum and soleus tissue homogenates. To measure MDA in the soleus tissue, cell lysates were prepared as follows: a $10 \%(\mathrm{w} / \mathrm{v})$ soleus in $50 \mathrm{mM}$ phosphate buffer ( $\mathrm{pH}$ 7.4) was made; then, the debris was removed by centrifugation at $12,000 \times \mathrm{g}$ for $30 \mathrm{~min}$ at $4{ }^{\circ} \mathrm{C}$ in a precooled centrifuge (Beckman Coulter, Inc, USA) and stored at $-70{ }^{\circ} \mathrm{C}$ until analysis. Then thiobarbituric acid $(0.6 \%)$ and acetic acid $(20 \%)$ were mixed and incubated in a water bath at $90{ }^{\circ} \mathrm{C}$ for $1 \mathrm{~h}$. The mixture was cooled on ice and received a mixture of butanol: pyridine (15:1) plus the samples (diluted 1:40in distilled water) vortexed and centrifuged. Finally, absorbance of the colored supernatant was measured at $535 \mathrm{~nm}$. The results were expressed as nmol/l. Total antioxidant capacity was determined by Randox total antioxidant status kit (cat no. nx 2332, Randox Company, Crumlin, UK) that is performed as followed, RANDOX $\operatorname{ABTS}^{\circ}\left(2,2^{\prime}\right.$ azino-di-[3-ethylbenzthiazoline sulphonate]) was incubated with a peroxidase (metmyoglobin) and $\mathrm{H}_{2} \mathrm{O}_{2}$ to produce the radical cation $\mathrm{ABTS}^{* *}+$. This has a relatively stable blue-green color, which is measured at $600 \mathrm{~nm}$. Antioxidants in the added sample cause suppression of this color production to a degree, which is proportional to their concentration.

Also, serum total cholesterol (TC), triglycerides (TG), high-density lipoprotein cholesterol (HDL-C), and lowdensity lipoprotein cholesterol (LDL-C) were assayed using commercial available kits (Parsazmoon Inc, Tehran, Iran).

\section{Statistical analysis}

Sample size was determined by PASS sample size software. Resultant data were analyzed using SPSS (version19) through the independent $t$ student test. The results were expressed as mean \pm SD. Statistical significance is shown as $p \leq 0.05$.

\section{Results}

Effect of thyme supplementation on lipidic indices

Table 1 represents the effect of our treatments on weight and lipid profile of the rats. In the current study, the post weight of the supplemented group did not differ by non-supplemented group $(p=0.12)$ clearly indicated that the thyme extract supplementation did not effect on weight gain or loss. However, the total serum cholesterol and HDL-C are significantly lower in the supplemented group $\left(\mathrm{t}_{18}=3.51, p<0.01 ; \mathrm{t}_{18}=3.84, p<0.01\right.$ respectively $)$.

\section{Effect of thyme supplementation on maximal endurance capacity}

The most obvious finding to emerge from the analysis is that the exhaustive running time of rats in thyme extract supplemented group was significantly prolonged (over four times longer) compared to that of the non-supplemented group $\left(\mathrm{t}_{18}=4.05, p<0.01\right)$, Table 1 .

\section{Effect of thyme supplementation on serum and soleus muscle oxidative stress}

As shown in Table 2, MDA levels were significantly higher for the treatment group compared to those of the non-treated group both in serum and soleus muscle homogenate $\left(\mathrm{t}_{18}=8.11, p<0.01 ; \mathrm{t}_{18}=4.98, p<0.01\right.$ respectively), which showed elevated lipid peroxidation in the thyme supplemented group.

In addition, the results of experiments showed that there were no significant differences in hemolysate SOD and GPx activity as well as serum total antioxidant capacity between the supplemented and non-supplemented groups (Table 2). However, the activity of both SOD and GPx within the soleus muscle was significantly higher in the non-supplemented group vs. supplemented group. These results are presented in Table 2.

\section{Effect of thyme supplementation on protein expression of PGC-1a}

Thyme supplementation significantly $(p<0.05)$ reduced protein expression of PGC- $1 \alpha$ as observed in Fig. 1.

Table 1 Descriptive statistics of performance, weight and some of the lipidic indices

\begin{tabular}{lccccccc}
\hline & FEP (Seconds) & Pre-weight $(\mathrm{g})$ & Post-weight $(\mathrm{g})$ & TG $(\mathrm{mg} / \mathrm{dl})$ & Total -C $(\mathrm{mg} / \mathrm{dl})$ & $\mathrm{LDL}-\mathrm{C}(\mathrm{mg} / \mathrm{dl})$ & $\mathrm{HDL}-\mathrm{C}(\mathrm{mg} / \mathrm{dl})$ \\
\hline Non-Supp $(n=10)$ & $653.00 \pm 941.23$ & $250.40 \pm 9.32$ & $301.30 \pm 20.78$ & $51.90 \pm 6.10$ & $68.70 \pm 6.07$ & $17.20 \pm 4.31$ & $41.13 \pm 2.55$ \\
Supp $(n=10)$ & $3066.00 \pm 1631.06^{*}$ & $243.10 \pm 8.96$ & $297.00 \pm 32.49$ & $48.00 \pm 7.80$ & $59.90 \pm 5.09^{*}$ & $15.30 \pm 2.85$ & $35.00 \pm 4.35^{*}$ \\
\hline
\end{tabular}

Data are shown as mean \pm SD

FEP final endurance performance, TG triglycerides, Total-C total cholesterol, $L D L-C$ low density lipoprotein cholesterol, $H D L-C$ high density lipoprotein cholesterol, Non-Supp non-supplemented, Supp supplemented

${ }^{*} p<0.05$ was considered as significant 
Table 2 The results of independent $t$ test within different markers of oxidative stress

\begin{tabular}{lccc}
\hline & Non-Supp $(n=10)$ & Supp $(n=10)$ & $p$-values \\
\hline Serum SOD $(\mathrm{U} / \mathrm{ml})$ & $1262.50 \pm 155.95$ & $1160.00 \pm 112.33$ & 0.11 \\
Soleus SOD $(\mathrm{U} / \mathrm{mg})$ & $13.55 \pm 1.23$ & $10.46 \pm 0.71$ & $0.001^{*}$ \\
Serum GPx $(\mathrm{U} / \mathrm{gH})$ & $68.94 \pm 12.14$ & $72.51 \pm 14.26$ & 0.55 \\
Soleus GPx $(\mathrm{U} / \mathrm{mg})$ & $72.48 \pm 14.52$ & $56.41 \pm 10.02$ & $0.01^{*}$ \\
Serum MDA (umol/l) & $1.10 \pm 0.47$ & $3.52 \pm 0.82$ & $0.001^{*}$ \\
Soleus MDA (umol/g) & $0.51 \pm 0.28$ & $1.79 \pm 0.76$ & $0.001^{*}$ \\
Serum total antioxidant (mmol) & $1.34 \pm 0.37$ & $1.79 \pm 0.63$ & 0.07 \\
\hline
\end{tabular}

Data are shown as mean \pm SD

Non-Supp non-supplemented, Supp supplemented

${ }^{*} p<0.05$ was considered as significant

\section{Discussion}

The current research as a pioneer study investigated the possible effects of thymus migricus Klokov \& Desj.-Shost extract on endurance performance of rats as well as lipid peroxidation, antioxidant enzymes activity, total antioxidant capacity, muscular content of PGC1- $\alpha$ as a possible mechanism of effect. Results revealed that the exhaustive running time for the treatment group was significantly prolonged showing thyme extract supplementation increased endurance exercise tolerance in intact animals,
Also, the research findings showed that MDA levels in both serum and soleus muscle were significantly higher in the thyme extract supplemented group compared to those of the non-supplemented group, which indicated elevated lipid peroxidation in the thyme supplemented group, the fact that was in contrast with the research hypothesis. Regarding to longer running time (four fold) in the final endurance performance test for supplemented group, it seems that elevated MDA level in the supplemented group was due to the sever exercise (exhaustive

\section{PGC1a}

B-Actin
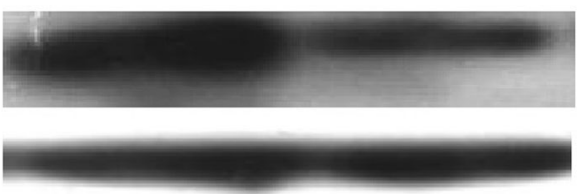

\section{Supplement Exercise}

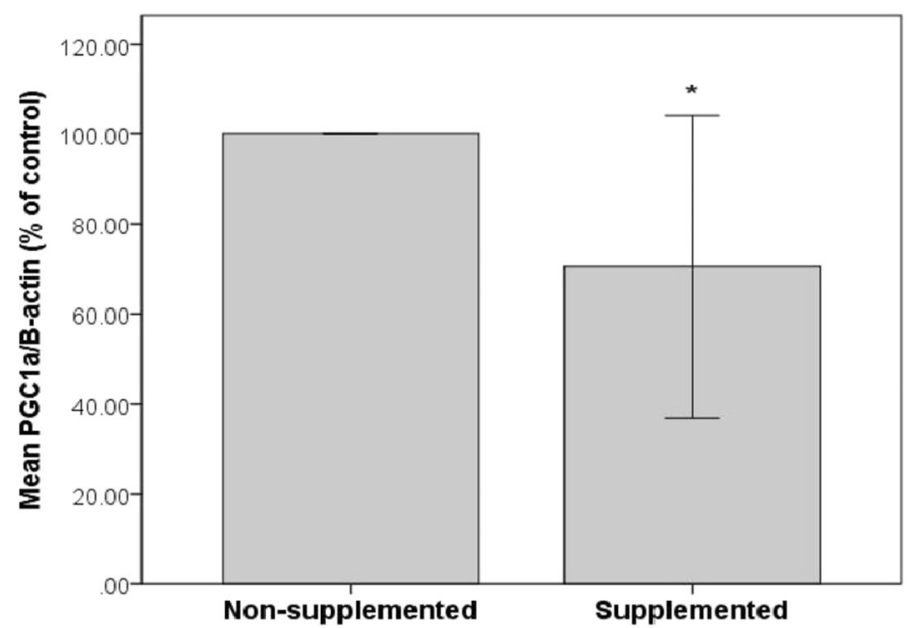

Fig. 1 Reduced expression of PGC1a in thyme extract supplemented exercised group in compare with non-supplemented rats. A, Western blot against PGC1a in soleus muscle from Thyme-supplemented and non-supplemented exercised Rats, followed by $24 \mathrm{~h}$ rest. B, Quantification of the bands Data has been shown in bottom panel ( $n=5$ /group). ${ }^{*}, p<0.05$ 
running time) rather than the direct effect of thyme supplementation. Study of Yavari et al. 2014 also indicated increased concentration of lipid peroxide after exercise [25]. The elevated levels of mitochondrial ROS during exercise arise from increased tissue and whole-body oxygen consumption. Increased metabolic rate and oxygen consumption by muscle fibers, augments temperature and reduces $\mathrm{pH}$ of muscle cells during the exercise, which might also hasten the generation of free radicals [25]. In addition, increased levels of catecholamines during exercise, as well as enhanced release of metmyoglobin from damaged muscles, and reciprocal action of metmyoglobin and methaemoglobin with peroxides throughout exercise have been similarly suggested as mediators of ROS generation [26]. As the intensity of training increases, the ROS production raises leading to endothelial hypoxia, which may cause a decrease in adenosine triphosphate (ATP) sources due to ATPdependent calcium ionic pump impairment and calcium-dependent proteases activation [27]. The proteolytic activity of these enzymes may result in cleavage of xanthine dehydrogenase and conversion to the oxidase form. Xanthine oxidase catalyzes a reaction which converts xanthine to uric acid and superoxide anions, $\mathrm{O}_{2}{ }^{--}$[27]. Therefore, ROS production increases and lipid peroxidation may develop. Furthermore, it is possible that the dosage of thyme extract was not enough to prevent lipid peroxidation and MDA production.

The present research also showed that there was no significant difference in serum SOD, GPx, and total antioxidant capacity between the supplemented and nonsupplemented groups. However, the activity of both SOD and GPx within the soleus muscle was significantly higher in the non-supplemented group. As mentioned earlier, these result can be explained by the same insight about MDA elevation.

Some studies have reported positive effect of distinct herbal extracts as supplements on antioxidant capacity [28-31], while our results are not in agreement with these studies. This contradiction may be due to the consequence of the tissues specific responses to ROS [32], different duration and intensity of the exercise, dissimilar sample collection methods, using various tissues, or application of different techniques for the measurement of oxidative stress [33].

The soleus muscle is one of the most active muscle groups during running, and it has high mitochondrial content. The augmented production of ROS in the soleus muscle after exhaustive running exercise and the subsequent decrease in the SOD and GPx reducing capacity in the treated group could be explained using body's antioxidant capacity to quench the damaging radical production [33]. The observed decrease in antioxidant enzyme activity may also reflect allosteric down-regulation of the enzymes, as well as enzyme inactivation assignable to overwhelming oxidative stress.

This study also showed that PGC- $1 \alpha$ content of soleus muscle decreased in the supplemented group. A PGC$1 \alpha$ effect on cellular ROS production is mediated by Sirt3, a downstream target gene of PGC-1 $\alpha$ [34]. Therefore, lower muscle content of PGC-1 $\alpha$ in the supplemented group possibly can explain elevated ROS generation and subsequent higher lipid peroxidation. This finding was consistent with other earlier ones utilizing different kinds of antioxidant supplements, in which PGC-1 $\alpha$, NRF-1, Tfam and cytochrome $C$ were detected to be down-regulated [35, 36]. Regarding down-regulation of PGC-1 $\alpha$ in thyme extract supplemented group, it is possible that chronic intake of powerful antioxidant like thyme extract hamper, and even inhibit the improving effect of exercise on physiological adaptations like mitochondrial biogenesis due to decreased levels of ROS in long-term. As mentioned earlier appropriate ROS levels act as a biological messenger, initiating cellular signaling cascades via the process of electron transfer to promote adaptive responses within the body [1]. Indeed, acute exercise induced modest level of oxidative stress can result in PGC- $1 \alpha$ upregulation through the activation of MAP kinases (p38 and ERK1/2), NF- $k B$, protein kinase B (Akt), mammalian target of rapamycin (mTOR), p70 ribosomal S6 kinase (p70s6K) pathway [37] and thyme supplementation may inhibit these events. This rather contradictory result may be due to the high dosage of long term thyme extract supplementation in the present study which alleviated the positive effects of moderate exercise-induced ROS.

According to the findings of this study, the exhaustive running time of rats in thyme extract supplemented group was significantly prolonged compared to the nonsupplemented group, which can be the most practical and predominant finding of this study. This result suggested that thyme supplementation could elevate the exercise tolerance of rats. Although no study has directly examined the effect of thyme extract supplementation on endurance performance, others have reported positive effects of different poly-phenolic compounds $[15,18-20]$. Such an improvement in performance seems to be related to cardiovascular, chemopreventive, immunological, or other adaptations [37] rather than mitochondrial biogenesis (due to lower content of PGC-1 $\alpha$ in the supplemented group). In this regard, some researchers also showed that PGC-1 $\alpha$ KO mice have regular voluntary running activity in spite of diminished basal mitochondrial respiratory activity [38], indicating that PGC-1 $\alpha$ up-regulation may be helpful but not necessary in promoting endurance running performance. This disparity could be related to compensatory accommodations in various tissues 
because of the down-regulation of the PGC-1 $\alpha$. This result may also be explained by the fact that thyme supplementation has led to decreased hematocrit, hemoglobin and mean corpuscular hemoglobin concentration, all important in determining blood viscosity, (data not reported but available on request). It is well accepted that low viscosity of blood has direct positive correlation with cardiac output, oxygen delivery to the tissue, maximum oxygen consumption, lipid oxidation during exercise, and endurance performance [39]. In this way, thyme extract supplementation can help athletes to improve their endurance capacity. This combination of findings provides some support for the practical effects of thyme supplementation to improve endurance performance regardless of molecular alterations. However, further studies are needed to understand the exact molecular mechanisms. Furthermore, it is suggested to other researchers to take samples at different times (immediately, 24 and $48 \mathrm{~h}$ following exercise) and use lower dosage of thyme extract to better understand the effect of this extract on oxidative stress, lipid peroxidation, antioxidants levels and markers of mitochondrial biogenesis.

\section{Conclusion}

Thyme extract supplementation increased endurance exercise tolerance in intact animals, although decreased oxidative stress and regulation of the PGC- $1 \alpha$ protein expression are not considered as underlying molecular mechanisms.

\begin{abstract}
Abbreviations
ATP: Adenosine triphosphate; CAT: Catalase; CK: Creatine kinase; CRP: Creactive protein; $\mathrm{ECL}$ : Enhanced chemiluminescence;

EDTA: Ethylenediaminetetraacetic acid; FEP: Final endurance performance: GPX: Glutathione peroxidase; HDL-C: High-density lipoprotein cholesterol; HRP: Horseradish peroxidise; IL-6: Interleukin-6; KO: Knock out; LDL-C: Lowdensity lipoprotein cholesterol; MDA: Malondialdehyde; Mon: Monocyte; NADP: Nicotinamide adenine dinucleotide phosphate; Non-Supp: Nonsupplemented group; PBS-BSA-T buffer: Phosphate buffered saline- Bovine serum albumin-Tween-20 buffer; PGC-1a: Peroxisome proliferator-activated receptor coactivator; PVDF: Polyvinylidene difluoride; RBC: Red blood cell; ROS: Reactive oxygen species; SIRT3: Sirtuin 3; SOD: Superoxide dismutase; Supp: Supplemented group; TBA: Thiobarbituric acid; TG: Triglycerides; TotalC: Total cholesterol
\end{abstract}

\section{Acknowledgments}

Special thanks go to Dr Farhoudi for allowing to use laboratory and animal breeding center of the Neuroscience Research Center.

\section{Funding}

The funds for this study were provided half by Dr. Pouran Karimi and half by Dr, Mostafa Khani. These funds were used to purchase the necessary supplies and pay the article-processing charges.

\section{Availability of data}

Data are all contained within the article.

\section{Authors' contributions}

MK participated in whole steps, including animal care, training and molecular tests and draft the manuscript. PM participated in the plan of the study. MRD drafted the manuscript. SDN participated in the statistical analyzing. PK performed the coordination and helped to biochemical and immunoblotting studies. All authors confirmed the current manuscript. All authors read and approved the final manuscript.

\section{Competing interests}

The authors declare that they have no competing interests.

Consent for publication

Not applicable.

\section{Ethics approval}

All aspects of this experimental protocol were approved (approval number 7-675904) by Animal Care and Use Committee of Kharazmi University

(Tehran, Iran). The study was conducted in accordance with the

requirements of the declarations of Helsinki.

\section{Publisher's Note}

Springer Nature remains neutral with regard to jurisdictional claims in published maps and institutional affiliations.

\section{Author details}

${ }^{1}$ Faculty of Physical Education and Sport Sciences, University of Tabriz, Tabriz, Iran. ${ }^{2}$ Faculty of Physical Education and Sport Sciences, Kharazmi University, Tehran, Iran. ${ }^{3}$ Neurosciences Research Center, Tabriz University of Medical Sciences, Tabriz, Iran.

Received: 26 July 2015 Accepted: 14 April 2017

Published online: 21 April 2017

References

1. Powers SK, Duarte J, Kavazis AN, Talbert EE. Reactive oxygen species are signalling molecules for skeletal muscle adaptation. Exp Physiol. 2010;95:1-9.

2. Halliwell B, Gutteridge J. Free radicals in biology and medicine. NY: Oxford University Press; 2011. Series Editor.

3. Dröge W. Free radicals in the physiological control of cell function. Physiol Rev. 2002:82:47-95.

4. Finaud J, Scislowski V, Lac G, Durand D, Vidalin H, Robert A, Filaire E. Antioxidant status and oxidative stress in professional rugby players: Evolution throughout a season. Int J Sports Med. 2006;27:87-93.

5. Itoh H, Ohkuwa T, Yamazaki Y, Shimoda T, Wakayama A, Tamura S, Yamamoto T, Sato Y, Miyamura M. Vitamin e supplementation attenuates leakage of enzymes following 6 successive days of running training. Int J Sports Med. 2000:21:369-74.

6. Meeusen R, Duclos M, Gleeson M, Rietjens G, Steinacker J, Urhausen A. Prevention, diagnosis and treatment of the overtraining syndrome: Ecss position statement 'task force'. Eur J Sport Sci. 2006;6:1-14.

7. Slattery K, Bentley D, Coutts AJ. The role of oxidative, inflammatory and neuroendocrinological systems during exercise stress in athletes: Implications of antioxidant supplementation on physiological adaptation during intensified physical training. Sports Med. 2015;45:453-71.

8. Watson TA, MacDonald-Wicks LK, Garg ML. Oxidative stress and antioxidants in athletes undertaking regular exercise training. Int J Sport Nutr Exerc Metab. 2005;15:131-46.

9. Ji LL. Modulation of skeletal muscle antioxidant defense by exercise: role of redox signaling. Free Radic Biol Med. 2008;44:142-52.

10. Palazzetti S, Rousseau A-S, Richard M-J, Favier A, Margaritis I. Antioxidant supplementation preserves antioxidant response in physical training and low antioxidant intake. Br J Nutr. 2004:91:91-100.

11. Watson TA, Callister R, Taylor RD, Sibbritt DW, MacDonald-Wicks LK, Garg $\mathrm{ML}$. Antioxidant restriction and oxidative stress in short-duration exhaustive exercise. Med Sci Sports Exerc. 2005;37:63-71.

12. Rousseau A-S, Hininger I, Palazzetti S, Faure H, Roussel A-M, Margaritis I. Antioxidant vitamin status in high exposure to oxidative stress in competitive athletes. Br J Nutr. 2004;92:461-8.

13. Howatson G, McHugh M, Hill J, Brouner J, Jewell A, Van Someren KA, Shave $\mathrm{R}$, Howatson S. Influence of tart cherry juice on indices of recovery following marathon running. Scand J Med Sci Sports. 2010;20:843-52.

14. Arent SM, Pellegrino JK, Williams CA, DiFabio DA, Greenwood JC. Nutritional supplementation, performance, and oxidative stress in college soccer players. J Strength Cond Res. 2010;24:1117-24. 
15. Davis M, Murphy A, Carmichael MD, Davis B. Quercetin increases brain and muscle mitochondrial biogenesis and exercise tolerance. Am J Physiol Regul Integr Comp Physiol. 2009;296:1071-7.

16. Lagouge M, Argmann C, Gerhart-Hines Z, Meziane H, Lerin C, Daussin F, Messadeq N, Milne J, Lambert P, Elliott P. Resveratrol improves mitochondrial function and protects against metabolic disease by activating sirt1 and pgc-1a. Cell. 2006;127:1109-22.

17. Steiner JL, Murphy EA, McClellan JL, Carmichael MD, Davis JM. Exercise training increases mitochondrial biogenesis in the brain. J Appl Physiol. 2011;111:1066-71.

18. Nieman DC, Williams AS, Shanely RA, Jin F, McAnulty SR, Triplett NT, Austin $M D$, Henson DA. Quercetin's influence on exercise performance and muscle mitochondrial biogenesis. Med Sci Sports Exerc. 2010;42:338-45.

19. Belviranlı M, Gökbel H, Okudan N, Başaralı K. Effects of grape seed extract supplementation on exercise-induced oxidative stress in rats. $\mathrm{Br} \mathrm{J}$ Nutr. 2012;108:249-56.

20. Murase T, Haramizu S, Shimotoyodome A, Tokimitsu I, Hase T. Green tea extract improves running endurance in mice by stimulating lipid utilization during exercise. Am J Physiol Regul Integr Comp Physiol. 2006;290:R1550-6.

21. Geng T, Li P, Okutsu M, Yin X, Kwek J, Zhang M, Yan Z. Pgc-1a plays a functional role in exercise-induced mitochondrial biogenesis and angiogenesis but not fiber-type transformation in mouse skeletal muscle. Am J Physiol Cell Physiol. 2010;298:C572-9.

22. Moshafi MH, Mansouri S, Sharififar F, Khoshnoodi M, Pharm D. Antibacteria and antioxidant effects of the essential oil and extract of zataria multiflora boiss. J Kerman Univ Med Sci. 2007;14:33-43.

23. Naghdi Badi HA, Maki zadeh Tafti M. A review on thymus vulgaris. J Med Plants. 2003;7:12-1.

24. Ramazani M, Hosein Zadeh H, Sami Zadeh S. Analgesic effects of zataria multiflora leaves functions on mice [in persian]. Iran J Basic Med Sci. 2001;4:233-23.

25. Yavari A, Javadi M, Mirmiran P, Bahadoran Z. Exercise-induced oxidative stress and dietary antioxidative. 2014.

26. Powers SK, Jackson MJ. Exercise-induced oxidative stress: cellular mechanisms and impact on muscle force production. Physiol Rev. 2008;88: 1243-76.

27. Lamprecht M, Greilberger J, Oettl K. Analytical aspects of oxidatively modified substances in sports and exercises. Nutrition. 2004;20:728-30

28. Nishizawa M, Hara T, Miura T, Fujita S, Yoshigai E, Ue H, Hayashi Y, Kwon AH, Okumura T, Isaka T. Supplementation with a flavanol-rich lychee fruit extract influences the inflammatory status of young athletes. Phytother Res. 2011; 25:1486-93.

29. Skarpanska-Stejnborn A, Pilaczynska-Szczesniak L, Basta P, Deskur-Smielecka E, Woitas-Slubowska D, Adach Z. Effects of oral supplementation with plant superoxide dismutase extract on selected redox parameters and an inflammatory marker in a 2,000-m rowing ergometer test. Int J Sport Nutr Exerc Metab. 2011;21:124.

30. Giacomo CD, Acquaviva R, Sorrenti V, Vanella A, Grasso S, Barcellona ML, Galvano F, Vanella L, Renis M. Oxidative and antioxidant status in plasma of runners: effect of oral supplementation with natural antioxidants. J Med Food. 2009;12:145-50.

31. Kelkar G, Subhadra K, Chengappa RK. Effect of antioxidant supplementation on hematological parameters, oxidative stress and performance of indian athletes. J Hum Ecol. 2008;24:209-13.

32. MacDougall D, Sale D. The physiology of training for high performance. Oxford: Oxford University Press; 2014 (Series Editor).

33. Fisher-Wellman K, Bloomer RJ. Acute exercise and oxidative stress: A 30 year history. Dyn Med. 2009:8:1.

34. Kong X, Wang R, Xue Y, Liu X, Zhang H, Chen Y, Fang F, Chang Y. Sirtuin 3, a new target of pgc-1alpha, plays an important role in the suppression of ros and mitochondrial biogenesis. PLoS One. 2010;5:e11707.

35. Sun Y, Qi Z, He Q, Cui D, Qian S, Ji L, Ding S. The effect of treadmill training and nac intervention on biogenesis of cytochrome c oxidase (cox). Free Radic Biol Med. 2015;87:326-35.

36. Kwon SM, Park HG, Jun JK, Lee WL. Exercise, but not quercetin, ameliorates inflammation, mitochondrial biogenesis, and lipid metabolism in skeletal muscle after strenuous exercise by high-fat diet mice. J Exerc Nutrition Biochem. 2014;18:51

37. Sandoval-Acuña C, Ferreira J, Speisky H. Polyphenols and mitochondria: an update on their increasingly emerging ros-scavenging independent actions. Arch Biochem Biophys. 2014:559:75-90.
38. Adhihetty PJ, Uguccioni G, Leick L, Hidalgo J, Pilegaard H, Hood DA. The role of pgc-1a on mitochondrial function and apoptotic susceptibility in muscle. Am J Physiol Cell Physiol. 2009;297:C217-25.

39. Nikookheslat SD, Khani M, Sadri K, Azadi B. The effect of exercise induced hemorheological adaptation on respiratory function and sport performance. Asian J Med Pharm Res. 2013;3:161-75.

\section{Submit your next manuscript to BioMed Central and we will help you at every step:}

- We accept pre-submission inquiries

- Our selector tool helps you to find the most relevant journal

- We provide round the clock customer support

- Convenient online submission

- Thorough peer review

- Inclusion in PubMed and all major indexing services

- Maximum visibility for your research

Submit your manuscript at www.biomedcentral.com/submit

) Biomed Central 